\title{
PENDAMPINGAN PENGELOLAAN PERPUSTAKAAN UNTUK MENDUKUNG GERAKAN LITERASI SEKOLAH
}

\section{Desi Eri Kusumaningrum*, Imam Gunawan, Raden Bambang Sumarsono, Teguh Triwiyanto}

Jurusan Administrasi Pendidikan, Fakultas Ilmu Pendidikan, Universitas Negeri Malang, Indonesia Jalan Semarang Nomor 5, Malang

*e-mail: desi.eri.fip@um.ac.id

\begin{abstract}
The aim of community service is the establishment of a good and correct library management system for the two partner schools and the preparation of a primary school library management manual. The target audience includes 2 partner schools, namely SDN Sentul 1 and SDN Sentul 2, Purwodadi District, Pasuruan Regency. This activity involved the Community Service Team consisting of 4 lecturers and 4 students as resource persons and assistants, and teachers in 2 partner schools who served as librarians in each school. The method of implementation is the classical approach and individual approach. This library management assistance activity produced results in the form of a library management system in the two partner schools properly and correctly. Based on the results of the evaluation, it can be concluded that this service activity was successful in achieving its objectives. The benefit that can be obtained through this activity is the strengthening of the school literacy movement.
\end{abstract}

Keywords: Mentoring activities; library management; school literacy movement

\begin{abstract}
Abstrak: Tujuan pengabdian kepada masyarakat ini yaitu tersusunnya sistem pengelolaan bahan pustaka yang baik dan benar pada kedua sekolah mitra dan tersusunnya buku panduan pengelolaan perpustakaan sekolah dasar. Khalayak sasaran kegiatan ini meliputi 2 sekolah mitra yaitu SDN Sentul 1 dan SDN Sentul 2 Kecamatan Purwodadi Kabupaten Pasuruan. Kegiatan ini melibatkan Tim Pengabdian Kepada Masyarakat yang terdiri dari 4 orang dosen dan 4 orang mahasiswa sebagai narasumber dan pendamping, dan guru di 2 sekolah mitra yang bertugas sebagai pustakawan di masing-masing sekolah. Metode pelaksanaan yaitu pendekatan klasikal dan pendekatan individual. Kegiatan pendampingan pengelolaan perpustakaan ini memberikan hasil berupa tersusunnya sistem pengelolaan bahan pustaka pada kedua sekolah mitra dengan baik dan benar. Berdasarkan hasil evaluasi, dapat disimpulkan bahwa kegiatan pengabdian ini berhasil dalam mencapai tujuan. Manfaat yang bisa diperoleh melalui kegiatan ini yaitu terjadi penguatan gerakan literasi sekolah.
\end{abstract}

Kata kunci: Kegiatan pendampingan; pengelolaan perpustakaan; gerakan literasi sekolah 


\section{PENDAHULUAN}

Perpustakaan memegang peranan penting dalam meningkatkan minat baca dan penciptaan masyarakat belajar, demikian halnya perpustakaan sekolah. Perpustakaan sekolah merupakan sarana pendidikan yang strategis, karena selain sebagai penunjang kegiatan pembelajaran, juga sebagai salah satu barometer standar mutu sekolah. Namun kenyataannya tidak semua sekolah, terutama Sekolah Dasar (SD) memiliki fasilitas perpustakaan sekolah yang ideal dalam hal manajerial, ketenagaan, pengelolaan, pengadaan, serta penataan bahan pustaka. Hanya sekolahsekolah tertentu yang memiliki sistem perpustakaan yang memadahi dan memiliki sistem manajerial yang profesional.

Sekolah sebagai organisasi pembelajaran perlu mengupayakan warga sekolahnya tumbuh sebagai pembelajar sepanjang hayat. Untuk menumbuhkan budaya belajar sepanjang hayat, pemerintah melalui Peraturan Menteri Pendidikan dan Kebudayaan Nomor 23 tahun 2015 tentang Penumbuhan Budi Pekerti, menyelipkan adanya kegiatan membaca buku non-pelajaran. Hal ini dimaksudkan agar tumbuh budaya baca di lingkungan warga sekolah utamanya peserta didik, sehingga minat baca meningkat dan penguasaan pengetahuan peserta didik dapat berkembang dengan baik.

Sekolah Dasar Negeri Sentul 1 (Mitra 1) dan Sekolah Dasar Negeri Sentul 2 (Mitra 2) merupakan sekolah negeri dibawah naungan Dinas Pendidikan dan Kebudayaan Kabupaten Pasuruan. Kedua sekolah ini terletak di Desa Sentul Kecamatan Purwodadi Kabupaten Pasuruan yang merupakan perbatasan antara Kabupaten Malang dan Kabupaten Pasuruan. Sehingga secara geografis kedua sekolah ini terletak di lingkaran paling luar dari Kabupaten Pasuruan.

SDN Sentul 1 didirikan pada tahun 1956 dengan menempati area seluas $5360 \mathrm{~m} 2$, sekolah ini memiliki tujuh rombel dengan sembilan ruangan. Jumlah tenaga pendidik yang dimiliki sebanyak 10 orang dan dibantu oleh satu orang tenaga kependidikan. Sementara jumlah peserta didik sebesar 253 orang yang terdiri dari 153 peserta didik laki-laki dan 100 orang peserta didik perempuan.

Sekolah ini tidak memiliki gedung perpustakaan sendiri, sehingga perpustakaan bergabung dengan ruangan lainnya. Koleksi bahan pustaka di sekolah ini cukup memadai namun belum terkelola dengan baik. Sehingga pemanfaatan perpustakaan untuk menunjang pembelajaran di sekolah belum dapat dilaksanakan dengan optimal. Kondisi yang tidak jauh berbeda ditemukan juga di perustakaan sekolah Mitra 2 yang dalam kegiatan ini merupakan sekolah dasar negeri yang mulai berdiri pada tahun 1910 dan secara geografis memiliki kesamaan dengan Mitra 1. Sekolah ini masih dalam satu wilayah desa dengan Mitra 1 namun berbeda dusun. Sekolah ini memiliki luas lahan sebesar $1658 \mathrm{~m} 2$ dengan tujuh tenaga pendidik dan satu tenaga kependidikan. Jumlah peserta didik pada sekolah ini sebanyak 114 orang yang terbagi menjadi 57 peserta didik laki-laki dan 57 peserta didik perempuan. SDN Sentul 2 ini memiliki enam rombel dengan enam ruangan kelas serta satu ruangan perpustakaan.

Kedua sekolah ini merupakan satu-satunya sekolah pilihan bagi masyarakat pada masingmasing dusun dalam menyekolahkan anak-anak mereka. Usia sekolah yang sudah lama, kedua sekolah ini mestinya sudah banyak perubahan yang bisa ditemukan dari sisi pelayanan kepada peserta didik. Namun tampaknya untuk mendukung pembelajaran, perpustakaan yang dimiliki sekolah tidak dapat memenuhi kebutuhan peserta didik dikarenakan belum terkelolanya perpustakaan dengan baik.

Permasalahan mitra yang akan dipecahkan melalui program ini adalah hal-hal yang menyangkut pada persoalan a) belum dilakukan proses klasifikasi seluruh bahan pustaka yang dimiliki oleh sekolah, b) belum dilakukan proses katalogisasi dengan baik sehingga tidak semua 
bahan pustaka terdokumentasi dengan baik, dan c) belum dilakukan proses pengaturan bahan pustaka dengan benar sesuai dengan pedoman yang ada

Program ini dilaksanakan dengan tujuan untuk memahami kondisi riil yang ada di lapangan tentang pengelolaan perpustakaan SD sebagai bagian penting dalam mendukung upaya gerakan literasi sekolah serta meningkatkan minat baca siswa. Program ini diharapkan bermanfaat bagi SD Mitra dalam mengelola perpustakaan sekolah dengan prinsip-prinsip dasar pengelolaan perpustakaan yang mendukung upaya gerakan literasi sekolah. Selain itu, program ini sangat bermanfaat dalam memberikan motivasi siswa untuk membaca dan memanfaatkan fasilitas perpustakaan sekolah.

\section{METODE}

Bertolak pada permasalahan yang dihadapi mitra, maka solusi yang dirancang oleh pengusul untuk menanggulangi permasalahan tersebut adalah dengan melakukan pengelolaan bahan pustaka yang dimiliki kedua perpustakaan mitra dilakukan sesuai dengan pedoman yang digunakan secara umum.

Realisasi pemecahan masalah dilakukan dengan menggunakan dua pendekatan yaitu pendekatan klasikal dan pendekatan individual. Pendekatan klasikal dilaksanakan pada kegiatan penyampaian materi oleh nara sumber yang diikuti oleh seluruh guru pada kedua sekolah mitra. Pendekatan ini dipilih berdasarkan pertimbangan bahwa setiap guru pada sekolah tersebut akan berkesempatan untuk diberikan tugas tambahan sebagai pustakawan sekolah. Sedangkan pendekatan individual dilaksanakan pada kegiatan pengelolaan bahan pustaka yang dilaksanakan oleh pembantu pelaksana (mahasiswa) dengan berkonsultasi dan berkoordinasi dengan dosen (nara sumber) dan 2 orang guru pada masing-masing sekolah mitra yang bertugas sebagai pustakawan pada saat ini.

Sasaran yang strategis dalam kegiatan Pengabdian Kepada Masyarakat ini yaitu Sekolah Dasar Negeri Sentul 1 (Mitra 1) dan Sekolah Dasar Negeri Sentul 2 (Mitra 2). SD tersebut merupakan sekolah negeri dibawah naungan Dinas Pendidikan dan Kebudayaan Kabupaten Pasuruan. Kedua sekolah ini terletak di Desa Sentul Kecamatan Purwodadi Kabupaten Pasuruan yang merupakan perbatasan antara Kabupaten Malang dan Kabupaten Pasuruan. Pada saat kegiatan pendampingan, masing-masing sekolah mitra melibatkan 2 orang guru yang bertugas sebagai pustakawan.

\section{HASIL DAN PEMBAHASAN}

Kegiatan pengelolaan tersebut dimulai dari proses klasifikasi bahan pustaka, katalogisasi, dan penyusunan bahan pustaka. Pelaksanaan kegiatan pengabdian kepada masyarakat ini dengan menggunakan 2 metode, yaitu 1) metode klasikal, dan 2) metode individual. Metode klasikal digunakan pada saat kegiatan penyampaian materi tentang pengelolaan perpustakaan sekolah oleh nara sumber. Penyampaian materi oleh 4 nara sumber dilakukan pada tanggal 12 Mei 2018 dan diikuti oleh seluruh guru pada kedua sekolah mitra sejumlah 17 orang. Pada kegiatan ini disampaikan pemaparan materi tentang Konsep dasar Perpustakaan Sekolah, Klasifikasi Bahan Pustaka, Katalogisasi, dan Penyusunan Bahan Pustaka.

Proses klasifikasi merupakan proses pengelompokan bahan pustaka sekolah atas dasar tertentu serta diletakkan secara bersama-sama dalam suatu tempat (Bafadal, 2011). Tujuan klasifikasi menurut Basuki (1991) sebagai penyusunan buku di rak dan sebagai sarana penyusunan entri bibliografi didalam katalog tercetak, bibliografi, dan indeks dalam tata susunan sistematis. Sementara itu Suwarno (2011) melihat tujuan klasifikasi dari sisi pengguna yakni agar pengguna dapat lebih mudah dalam menelusuri bahan pustaka yang dicari secara cepat dan tepat. Klasifikasi yang dilaksanakan pada sekolah mitra dengan menggunakan sistem klasifikasi Dewey Decimal Classification yang digunakan di perpustakaan seluruh dunia. 
Proses kedua yang dilakukan adalah katalogisasi. Katalog merupakan suatu daftar yang berisi keterangan-keterangan yang lengkap (komprehensif) dari suatu buku-buku koleksi, dokumen-dokumen, atau bahan-bahan pustaka lainnya (Bafadal, 2011). Sementara itu, Suhendar (2010) mengemukakan bahwa fungsi katalog adalah sebagai daftar inventaris bahan pustaka dari suatu perpustakaan serta sebagai sarana temu balik bahan pustaka. Setelah proses katalogisasi, berikutnya adalah dilakukan proses penyusunan bahan pustaka. Namun sebelum proses tersebut dilakukan, bahan pustaka terlebih dahulu dilengkapi dengan perlengkapan yang harus dimiliki, yaitu label buku, kartu buku beserta kantongnya, dan slip tanggal. Satu persatu bahan pustaka akan dilengkapi dengan perlengkapan tersebut sebelum kemudian disusun di rak sesuai dengan klasifikasi yang tepat.

Kegiatan pendampingan kepada 2 orang pustakawan pada masing-masing sekolah mitra untuk melakukan kegiatan klasifikasi, katalogisasi, dan penyusunan bahan pustaka dengan menggunakan metode klasikal. Jadi setelah para guru mendapatkan materi tentang pengelolaan bahan pustaka, maka pendampingan intensif dilakukan secara individual kepada guru yang ditunjuk oleh kepala sekolah sebagai pustakawan. Guru pustakawan bersama-sama dengan mahasiswa (pembantu pelaksana) melakukan proses pengelolaan bahan pustaka mulai dari klasifikasi, katalogisasi, dan penyusunan bahan pustaka. Sebagai gambaran pelaksanaan kegiatan pengabdian kepada masyarakat, sebagaimana divisualisasikan pada Gambar 1 dan Gambar 2.

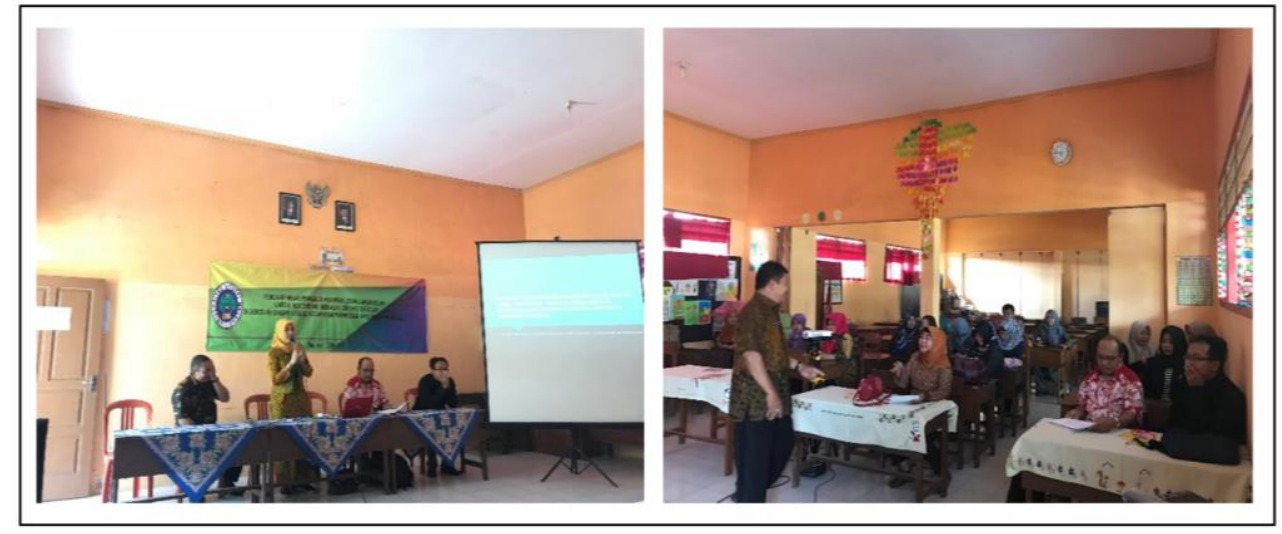

Gambar 1. Kegiatan Pendampingan dengan Menggunakan Metode Klasikal

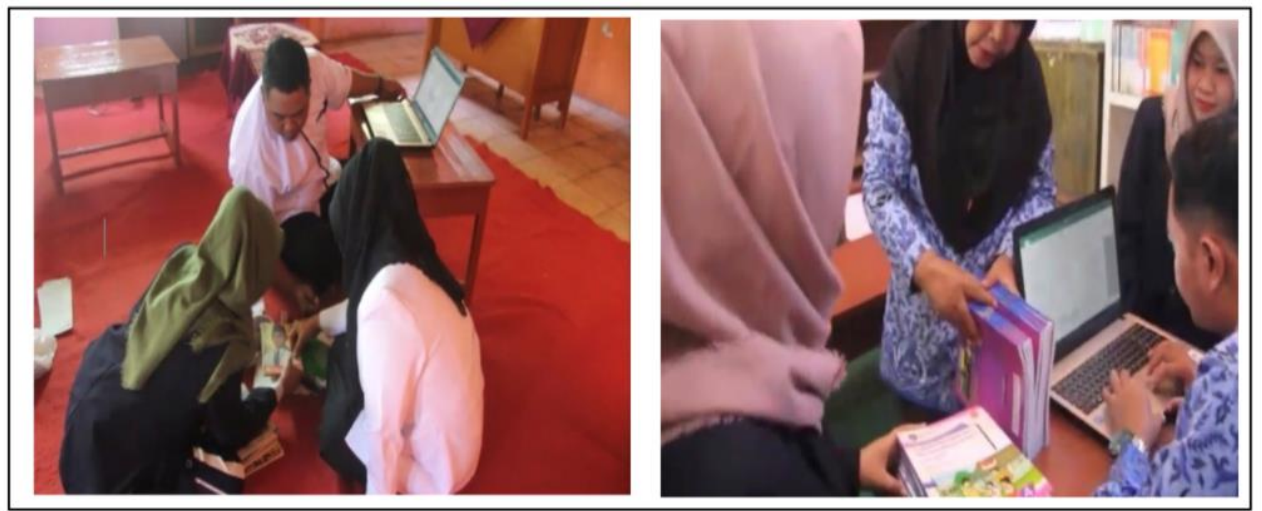

\section{Gambar 2. Kegiatan Pendampingan dengan Menggunakan Metode Individual}

Peran mahasiswa dalam hal ini adalah sebagai pendamping teknis guru pustakawan. Sehingga segala tahapan dalam pengelolaan bahan pustaka oleh guru selalu mendapatkan arahan dari mahasiswa yang tentunya selalu konsultasi dan koordinasi dengan dosen. Kegiatan ini memakan waktu 9 minggu dikarenakan koleksi pustaka pada kedua sekolah banyak. 
Kegiatan pendampingan pengelolaan perpustakaan ini memberikan hasil berupa tersusunnya sistem pengelolaan bahan pustaka pada kedua sekolah mitra dengan baik dan benar. Sistem klasifikasi bahan pustaka dan katalogisasi menggunakan system DDC (Dewey Decimal Code) yang memang sudah lazim digunakan pada sebagian besar perpustakaan di dunia. Sedangkan untuk penyusunan bahan pustaka diurutkan berdasarkan kode buku dan disusun berderet mulai dari samping kiri ke kanan. Untuk mempermudah pembaca melakukan penelusuran pustaka maka diberikan kode nomor buku pada tiap rak. Selain itu kelengkapan administrasi sirkulasi buku juga dilengkapi pada kegiatan pendampingan ini, sehingga ketika pembaca melakukan peminjaman sudah dapat direkam dengan baik meskipun masih memakai sistem manual.

Selain itu, kegiatan pengabdian masyarakat ini menghasilkan luaran berupa artikel yang sudah dimasukkan pada jurnal nasional Abdimas Pedagogi yang dikelola oleh Fakultas Ilmu Pendidikan Universitas Negeri Malang. Luaran berikutnya adalah Panduan Pengelolaan Perpustakaan Sekolah Dasar yang dapat digunakan oleh sekolah baik sekolah mitra ataupun sekolah yang lainnya dalam mengelola bahan pustaka yang mereka miliki.

Kegiatan pendampingan pengelolaan perpustakaan ini sangat bermanfaat dan dibutuhkan oleh pihak sekolah. Sebagai tindak lanjut (sustainbility) program pengabdian ini, penulis berencana akan membuat lanjutan program yang mengarah kepada pengelolaan perpustakaan digital. Mengingat bahwa kemajuan teknologi saat ini yang demikian canggih sangat memungkinkan untuk memberikan kemudahan bagi pengelola perpustakaan dalam mengelola bahan pustaka yang dimiliki.

Berdasarkan hasil evaluasi, dapat disimpulkan bahwa kegiatan pengabdian ini berhasil dalam mencapai tujuan. Banyak manfaat yang bisa diperoleh melalui kegiatan ini. Bagi Kepala Sekolah, melalui kegiatan pengabdian ini diharapkan dapat memainkan peranannya dalam memberikan pembinaan dan pendampingan terhadap para guru di sekolahnya yang diberi tugas sebagai pustakawan.

Kebermanfaatan lainnya dari kegiatan ini juga dirasakan oleh UM. Bagi UM, sebagai lembaga pendidikan tinggi di Malang, melalui LP2M dan fakultas, dapat melaksanakan tri dharma perguruan tinggi, yaitu turut berperan serta dalam mengembangkan mutu pendidikan di lembaga pendidikan sekitarnya. Bagi Dinas Pendidikan dan Kebudayaan Kabupaten Pasuruan, melalui kegiatan pelatihan ini secara langsung dapat membantu memberikan pemahaman serta keterampilan bagi para kepala sekolah dan guru dalam mewujudkan mutu pendidikan melalui pengelolaan perpustakaan. Dengan demikian Dinas Pendidikan dan Kebudayaan Kabupaten Pasuruan perlu melakukan kegiatan sejenis, untuk memantapkan hasil dari kegiatan ini.

Perpustakaan merupakan salah satu sumber belajar penting dalam proses pembelajaran. Menurut Undang-Undang Nomor 43 Tahun 2007 tentang Perpustakaan, dinyatakan bahwa "perpustakaan adalah institusi pengelola koleksi karya tulis, karya cetak, dan/atau karya rekam secara profesional dengan sistem yang baku guna memenuhi kebutuhan pendidikan, penelitian, pelestarian, informasi, dan rekreasi para siswa sebagai penggunaan perpustakaan." Dari definisi tersebut, maka perpustakaan sekolah merupakan perpustakaan yang berada di lingkungan sekolah, bertanggung jawab kepada kepala sekolah, dan bertugas untuk melayani seluruh sivitas akademika sekolah tersebut. Bafadal (2011) menyatakan bahwa perpustakaan sekolah itu merupakan sumber belajar, karena kegiatan yang paling tampak pada setiap kunjungan siswa adalah belajar, baik belajar masalah-masalah yang berhubungan langsung dengan mata pelajaran yang diberikan di kelas, maupun buku-buku lain yang tidak berhubungan langsung dengan mata pelajaran yang diberikan di kelas.

Penyelenggaraan perpustakaan sekolah, oleh Bafadal (2011) bukan hanya untuk mengumpulkan dan menyimpan bahan-bahan pustaka, tetapi dengan adanya penyelenggaraan perpustakaan sekolah diharapkan dapat membantu siswa dan guru menyelesaikan tugas-tugas dalam proses belajar mengajar. Sementara itu, Yusuf \& Suhendar (2007: 3) menyebutkan tujuan didirikannya perpustakaan tidak terlepas dari tujuan diselenggarakannya pendidikan sekolah secara keseluruhan, yaitu memberikan bekal kemampuan dasar kepada siswa, serta mempersiapkan mereka untuk mengikuti pendidikan menengah. 
Layanan perpustakaan pada intinya ditujukan untuk kepuasan penguna atau pemustaka. Kepentingan pengguna dalam memanfaatkan informasi yang tersedia di perpustakaan ada kalanya berbeda antara satu dengan yang lainnya. Perbedaan tersebut seharusnya dapat memotivasi pustakawan menambah pengetahuannya dalam bidangnya agar dapat memberi pelayanan maksimal bagi para pengguna.

Berkaitan dengan layanan perpustakaan, pustakawan dituntut bersikap ramah, sopan, tekun dan tidak cepat bosan, setiap memberi jawaban dari semua pertanyaan pengguna perpustakaan jika perlu memberikan jalan keluar membimbing dan mengarahkan setiap pengguna. Beranjak dari hal tersebut maka pustakawan harus memiliki kompetensi sehingga dapat menimbulkan pelayanan yang berkualitas sehingga pengguna dapat memperoleh informasi yang dibutuhkannya secara optimal dan memanfaatkan berbagai perkakas penelusuran yang tersedia.

\section{SIMPULAN}

Berdasarkan kegiatan pendampingan pengelolaan perpustakaan ini dapat disimpulkan bahwa kegiatan ini efektif untuk membentuk sistem pengelolaan perpustakaan yang baik pada sekolah mitra, dengan menggunakan pendekatan klasikal dan pendekatan individual. Sekolah mitra mampu melakukan klasifikasi bahan pustaka, katalogisasi, dan tersusunnya bahan pustaka di sekolah sasaran dengan menggunakan sistem yang sudah digunakan di sebagian besar perpustakaan di dunia. Pengelolaan bahan pustaka yang baik dapat meningkatkan minat baca peserta didik, sehingga mampu membentuk budaya baca di lingkungan sekolah. Dengan demikian dapat mendukung program literasi yang digalakkan oleh sekolah dan dinas pendidikan kabupaten setempat.

Berdasarkan kegiatan pendampingan ini beberapa masukan yang dapat penulis rumuskan sebagai berikut: 1) bagi Kepala Sekolah Mitra 1, hendaknya menyegerakan pembangunan gedung perpustakaan atau setidaknya memberikan ruang baca bagi siswa sehingga siswa dapat memanfaatkan waktu istirahat dengan membaca buku di perpustakaan. Selain itu penunjukan guru pustakawan berikut deskripsi tugas yang jelas perlu segera dilaksanakan agar perpustakaan dapat dibuka setiap saat. 2) bagi Kepala Sekolah Mitra 2, untuk menambah koleksi bahan pustaka dapat melakukan open donasi kepada masyarakat terutama orang tua wali murid sehingga ketersediaan bacaan yang mutakhir bagi siswa dapat terpenuhi. Dimungkinkan pula penambahan koleksi bahan pustaka melalui donasi 1 alumni 1 buku. 3) bagi Guru Pustakawan, agar senantiasa melakukan pembaharuan database bahan pustaka sehingga semua bahan pustaka dapat tercatat dengan lengkap. 4) bagi Universitas Negeri Malang, program ini perlu untuk ditindaklanjuti untuk tahuntahun mendatang dengan pola pendampingan pengelolaan perpustakaan berbasis digital.

\section{DAFTAR RUJUKAN}

Bafadal, I. (2011). Pengelolaan Perpustakaan Sekolah. Jakarta: Bumi Aksara.

Basuki, S. (1991). Pengantar Ilmu Perpustakaan. Jakarta: Gramedia Pustaka Utama.

Kementerian Pendidikan dan Kebudayaan. 2016. Buku Saku Gerakan Literasi Sekolah. Jakarta: Kemdikbud.

Peraturan Menteri Pendidikan dan Kebudayaan Nomor 23 tahun 2015 tentang Penumbuhan Budi Pekerti.

Suhendar, Y. (2010). Pedoman Katalogisasi: Cara Mudah Membuat Katalog Perpustakaan. Jakarta: Kencana.

Suwarno, W. (2011). Pengetahuan Dasar Kepustakaan; Sisi Penting Perpustakaan dan Pustakawan. Bogor: Ghalia Indonesia.

Undang-Undang Nomor 43 Tahun 2007 tentang Perpustakaan. Bandung: Citra Umbara.

Yusuf, M. P. \& Suhendar, Y. (2007). Pedoman Penyelanggaraan Perpustakaan sekolah. Jakarta: Kencana Prenada MediaGroup. 